\title{
TRANSFORMATION OF ETHYLBENZENE-M-XYLENE FEED OVER MCM-22 ZEOLITES WITH DIFFERENT ACIDITIES
}

\author{
$\underline{\text { Magdolna R. Mihályi }^{1 *}, \text { Márton Kollár }^{1} \text {, Szilvia Klébert }}{ }^{1}$, Vesselina Mavrodinova ${ }^{2}$
}

${ }^{1}$ Institute of Materials and Environmental Chemistry, Research Centre for Natural Sciences, Hungarian Academy of Sciences, Pusztaszeri út 59-67, Budapest 1025, Hungary

2 Institute of Organic Chemistry with Centre of Phytochemistry, Bulgarian Academy of Sciences, Acad. G. Bonchev str., bl. 9, 1113 Sofia, Bulgaria

\begin{abstract}
Transformation of ethylbenzene (EB, $22 \mathrm{wt} \%)$-m-xylene (78 wt\%) mixture was carried out over zeolite MCM-22 catalysts with different acidities. The modification of the number and strength of the acid sites was attained by: (i) dealumination by steaming and successive acid treatment and (ii) isomorphous substitution of framework $\mathrm{Al}$ for boron ([Al,B]MCM-22). The effect of platinum introduction was also investigated. The strong decrease in the Brønsted acidity, concomitant to the dealumination procedure, appears unfavorable since it leads to a drastic diminish of the degree of EB conversion, not compensated by satisfactory level of $\mathrm{m}$-xylene isomerization. [Al,B]MCM-22 is a modification with much better performance, most probably because it contains both strong, Al-connected acid sites but in lower amount than in the parent sample, and weaker borongenerated sites and practically no any Lewis sites.

Parent zeolite [Al]MCM-22 as well as B-substitution possess promising properties for ethylbenzene-m-xylene mixture transformation catalyst with adequate degree of $\mathrm{EB}$ conversion and extent of p-xylene approach to equilibrium as well as low xylene loss.
\end{abstract}

Keywords: Dealuminated and B-substituted zeolite MCM-22; Pt/H-MCM-22; Ethylbenzene $+\mathrm{m}$-xylene mixture transformation.

\footnotetext{
* Corresponding author. Tel.: 36-1-438-1100; fax: 36-1-325-7554.

E-mail address: mihalyi.magdolna@ttk.mta.hu
} 


\section{Introduction}

The improvement of the processes connected to the manufacturing of xylenes from $\mathrm{C}_{8}$ aromatics cut containing o-xylene, m-xylene and 20 to $40 \%$ ethylbenzene (EB), produced in catalytic reforming of naphtha and naphtha pyrolysis is an important task for researchers. The transformation of this mixed feed on acidic catalysts should be mainly directed to isomerization of the xylenes ingredients up to the equilibrium value and to EB dealkylation and disproportionation with a minimum loss of xylenes [1-3]. The rate of these reactions is not only influenced by the strength and the number of the acidic centers, but also by the pore size of the zeolites [4-8]. Two types of zeolites are applied for the industrial processing of the $\mathrm{C}_{8}$ aromatic feed. In the process using mordenite-based, large-pore zeolite as bifunctional catalyst, EB is mainly converted into xylenes, whereas EB dealkylation and disproportionation are the main reaction routes over medium-pore pentasil-based catalysts.

In our previous contribution the catalytic performance of zeolite [Al]MCM-22 with intermediate pore structure was studied for the first time in the conversion of ethylbenzene-mxylene mixed feed [9]. The results reveal the promising properties of this catalyst for the selective elimination of EB from $\mathrm{C}_{8}$ aromatics feed at admissible xylene loss, compared to that of the large-pore BEA and medium-pore ZSM-5 zeolites.

Several types of zeolites, with different structures and acidity characteristics, bifunctional or in their $\mathrm{H}$-form, have been examined in the latter process [4-8] and thoroughly reviewed by Degnan et al. [10] but not the zeolite MCM-22. This zeolite has a layer structure and, as such, is a member of the MWW family [11]. In a template directed synthesis, first a lamellar precursor (MCM-22(P)) is prepared. Each layer includes a two-dimensional 10-MR (ten membered-ring) sinusoidal channel system and a hexagonal-array of cups, having 12-MR openings on the external surface of the layer. In the precursor material both the intralayer channels and the interlayer space are filled with the organic template. By removing the template, the MCM-22 material is obtained. During this thermal decomposition, the adjacent parallel layers of the precursor are linked together through oxygen bridges and supercages are formed from the cups facing each other.

MCM-22 has found fast industrial application for production of EB through liquid-phase alkylation of benzene with ethylene at low temperature. It was shown that the acid sites located in the 12-MR surface cups are responsible for the high selectivity in this reaction. The reverse reaction over the same catalyst is only scarcely studied [12] while that of the conversion of $\mathrm{C}_{8}$ mixed isomerization feed has not been investigated yet, although MCM-22 
has a structure similar to those of the two commercial zeolite catalysts applied in the industrial process.

The particular structure of the zeolite MCM-22 holds out interesting opportunities for modification by different methods like dealumination [13-16], change in the Si/Al ratio $[17,18]$, etc. In the present work modified MCM-22 zeolites with varying composition of the building lattice elements and diverse number and strength of the acid sites were used for the selective transformation of EB in presence of m-xylene at high temperature and atmospheric pressure. Two methods for modification of this zeolite thoroughly studied by us before $[19,20]$, were applied for moderating the acidity of MCM-22: (i) dealumination by steaming and successive acid treatment and (ii) isomorphous substitution of framework $\mathrm{Al}$ for boron. Pt-loaded MCM-22 was also tested in this reaction in order to study the effect of introduction of hydrogenation agent.

\section{Experimental}

\subsection{Catalysts preparation}

The [Al]MCM-22 precursor for both modifications was prepared by hydrothermal synthesis applying rotating industrial autoclave $\left(\sim 1 \mathrm{~m}^{3}\right)$ according to the procedure described in Ref. [20]. The crystallization temperature and time were $418 \mathrm{~K}$ and 10 days, respectively. After washing with distilled water and drying at $343 \mathrm{~K}$, the preparation was calcined in air (programmed heating, $1.5 \mathrm{~K} / \mathrm{min}$ up to $823 \mathrm{~K}$ for $3 \mathrm{~h}$ ) in order to remove the template. Twofold ion exchange with $1 \mathrm{M} \mathrm{NH}_{4} \mathrm{NO}_{3}$ solution was applied for the preparation of its ammonium form. The $\mathrm{H}$-form of the sample with $\mathrm{Si} / \mathrm{Al}$ molar ratio of 16 was obtained by in situ decomposition of the $\mathrm{NH}_{4}{ }^{+}$-form in $\mathrm{N}_{2}$ at $823 \mathrm{~K}$ and is indicated as MCM-22 (Table 1). The procedure for dealumination [19] was carried out by steam treatment at $623 \mathrm{~K}\left(350^{\circ} \mathrm{C}\right)$ and $773 \mathrm{~K}\left(500^{\circ} \mathrm{C}\right)$, (samples designated as D350 and D500) followed by $0.5 \mathrm{M}$ oxalic (samples D350/Ox and D500/Ox) acid reflux at $373 \mathrm{~K}$ (Table 1).

In case of $[\mathrm{Al}, \mathrm{B}] \mathrm{MCM}-22$ zeolite, sodium tetraborate hydrate (borax) was used as a source of boron [20]. The template was removed in air at $853 \mathrm{~K}$ from both [Al]- and [Al,B]MCM-22 materials, then the calcined samples were ion exchanged with $\mathrm{NH}_{4} \mathrm{Cl}$ solution at room temperature. The Al content was determined by Atomic Adsorption Spectroscopy (AAS) after digestion of the samples with hydrofluoric acid. The boron concentration was measured by Induced Coupled Plasma (ICP) emission after sample extraction with $1 \mathrm{M} \mathrm{HCl}$ solution at $373 \mathrm{~K}$. By calculating the integrated absorbance of the bands at $3620 \mathrm{~cm}^{-1}$ in the FT-IR spectra of $[\mathrm{Al}, \mathrm{B}] \mathrm{MCM}-22$ and [Al]MCM-22, due to the stretching vibration of the 
acidic hydroxyls bridged between the framework $\mathrm{Si}$ and $\mathrm{Al}$ atoms, a ratio of about 0.5 was found [20] designating that in the boron-containing catalyst half of the acid sites are Alconnected Broensted sites. This ratio corresponds to the relative aluminum content of the samples determined by AAS (Table 1).

0.5 wt \% of Pt was loaded by incipient wetness impregnation method on the zeolite sample in the form of tetraammineplatinum(II) hydroxide hydrate precursor. The Pt-complex was decomposed in an oven at $673 \mathrm{~K}$ for $1 \mathrm{~h}$ in air. Before catalytic run it was reduced in $\mathrm{H}_{2}$ at $673 \mathrm{~K}$ for $1 \mathrm{~h}$ in order to obtain bifunctional $\mathrm{Pt} / \mathrm{H}$-zeolite sample.

\subsection{Catalysts characterization}

The structure and crystallinity of the samples were verified by a Philips PW 1810 powder diffractometer. The particle size and the morphology were examined using SEM (Hitachi). Adsorption isotherms were determined by $\mathrm{N}_{2}$ sorption at $77 \mathrm{~K}$ using a Quantachrome NOVA Automated Gas Sorption instrument. The specific surface area was calculated from the $\mathrm{N}_{2}$ adsorption capacity by the multiple BET method. The micropore volumes were estimated from the alpha-s plots.

IR spectra were recorded by a Nicolet FT-IR spectrometer Impact 400 using the wafer transmission technique. The wafers of the catalysts were activated in high vacuum at $673 \mathrm{~K}$ for 1 hour then contacted with pyridine (Py) at $473 \mathrm{~K}$ and 5.7 mbar Py pressure for $30 \mathrm{~min}$, cooled down to $373 \mathrm{~K}$ in Py atmosphere and degassed then at increasing temperatures. The spectra were obtained at room temperature by collecting 32 scans at a resolution of $2 \mathrm{~cm}^{-1}$. Spectra were normalized to wafer thickness of $5 \mathrm{mg} / \mathrm{cm}^{2}$.

The $\mathrm{NH}_{4}{ }^{+}$-ion exchange capacity (IEC) of the samples were characterized by TPAE (Temperature-Programmed Ammonia Evolution [21]) and presented in Table 1. About 300 $\mathrm{mg}$ of samples were heated from 453 to $873 \mathrm{~K}$ at a rate of $10 \mathrm{~K} / \mathrm{min}$ in a $20-\mathrm{ml} / \mathrm{min}$ flow of dry nitrogen. From the effluent $\mathrm{NH}_{3}$ was absorbed in distilled water. The $\mathrm{pH}$ of the absorbing solution was kept between $\mathrm{pH}=5.5$ and 6.0 by automatically titrating the absorbed $\mathrm{NH}_{3}$ with $0.1 \mathrm{M} \mathrm{HCl}$ solution. The ammonia, evolved from the sample between 423 and $823 \mathrm{~K}$ during TPAE run, was taken as equivalent with the IEC of the sample and the Brønsted acid site concentration of the deammoniated sample.

\subsection{Catalytic studies}

The test reaction has been carried out in a fixed-bed flow reactor at atmospheric pressure, reaction temperatures of $723 \mathrm{~K}$ and $683 \mathrm{~K}$ and various contact times. $\mathrm{N}_{2}$ carrier gas was 
passed through a saturator filled with a mixture of ethylbenzene and m-xylene (weight ratio $22 \%: 78 \%$ ) and equilibrated at $293.2 \mathrm{~K}$ so that almost equal partial pressure of $0.9 \mathrm{kPa}$ to be attained for both components of the mixture (boiling points $409.2 \mathrm{~K}$ and $412 \mathrm{~K}$ respectively). Adjusting of this ratio has been made regularly by controlling its value in the range of $\pm 1 \%$ with the bypass. On-line analysis of the reaction products has been performed using HP-GC with 25m FFAP capillary column.

\section{Results and discussion}

\subsection{Physicochemical characteristics of the samples}

The X-ray diffraction patterns (Fig. 1) show that between 5 and $152 \theta$ the intensity of the reflections for the samples steamed at $773 \mathrm{~K}$ and $623 \mathrm{~K}$ (D500 and D350) and their acidtreated varieties (D500/Ox and D350/Ox) is higher than that of the parent MCM-22 material. The enhanced intensity of these reflections also detected by $\mathrm{Wu}$ et al. [23] in case of dealuminated MCM-22 materials can be due, according to Camblor et al. [24] to the removal of $\mathrm{Al}$ from lattice positions. The authors found out that the XRD pattern of ITQ-1, the pure silica analog of MCM-22, was better resolved than those of [Al]MCM-22 and indicated an improved crystallinity. No diffraction peaks due to another crystalline phase were observed for our steamed and steamed/acid-leached materials.

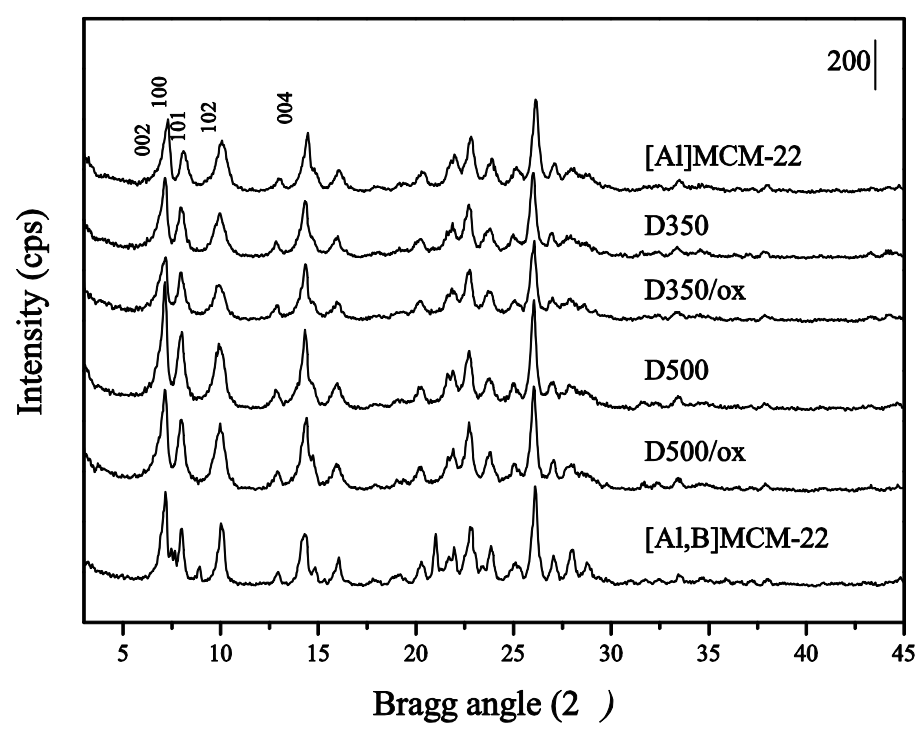

Figure 1. XRD pattern of the parent, dealuminated and boron-containing MCM-22 samples. 
According to the XRD data presented in Ref. [20] the boron modification, $[\mathrm{Al}, \mathrm{B}] \mathrm{MCM}-22$, is also well crystalline and phase-pure MCM-22 materials. The calculations based on the shift of the reflections in the XRD patterns used for determining the lattice $a$ and $c$ parameters showed that both these values are lower in case of the B-containing material. This result is an evidence, like in the case of [B]ZSM-5 [25] for boron incorporation in the MCM-22 framework which leads to significant lattice contraction.

Table 1. Aluminum content, ion-exchange capacity and textural properties of the samples.

\begin{tabular}{|c|c|c|c|c|c|c|c|}
\hline \multirow[t]{2}{*}{ Sample } & \multicolumn{2}{|c|}{$\begin{array}{l}\text { Dealumination } \\
\text { method }\end{array}$} & \multicolumn{2}{|c|}{ Aluminum content } & \multirow{2}{*}{$\begin{array}{c}\mathrm{IEC}^{\mathrm{a}, \mathrm{b}} \\
(\mathrm{mmol} / \mathrm{g})\end{array}$} & \multirow{2}{*}{$\begin{array}{l}\text { Surface } \\
\text { area } a, c \\
\left(\mathrm{~m}^{2} / \mathrm{g}\right)\end{array}$} & \multirow{2}{*}{$\begin{array}{c}\text { Micropore } \\
\text { volume }^{\mathrm{a}, \mathrm{d}} \\
\left(\mathrm{cm}^{3} / \mathrm{g}\right)\end{array}$} \\
\hline & Steaming & $\begin{array}{l}\text { Acid } \\
\text { reflux }^{\mathrm{a}}\end{array}$ & $\begin{array}{c}\mathrm{Si} / \mathrm{Al} \\
(\mathrm{mol} / \mathrm{mol})\end{array}$ & $\begin{array}{c}\Sigma \mathrm{Al}^{\mathrm{a}} \\
(\mathrm{mmol} / \mathrm{g})\end{array}$ & & & \\
\hline [Al]MCM-22 & - & - & 16.5 & 1.08 & 0.96 & 578 & 0.18 \\
\hline D350 & $623 \mathrm{~K}, 3 \mathrm{~h}$ & - & 22.3 & 1.12 & 0.72 & 528 & 0.16 \\
\hline $\mathrm{D} 350 / \mathrm{Ox}$ & $623 \mathrm{~K}, 3 \mathrm{~h}$ & $\begin{array}{l}\text { Oxalic } \\
24 \mathrm{~h}\end{array}$ & 25.6 & 0.68 & 0.63 & 526 & 0.16 \\
\hline D500 & $773 \mathrm{~K}, 3 \mathrm{~h}$ & - & 37.9 & 1.09 & 0.43 & 534 & 0.15 \\
\hline D500/Ox & $773 \mathrm{~K}, 3 \mathrm{~h}$ & $\begin{array}{l}\text { Oxalic } \\
24 \mathrm{~h}\end{array}$ & 45.4 & 0.69 & 0.36 & 538 & 0.15 \\
\hline [Al,B]MCM-22 & - & - & 32.2 & 0.46 & 0.75 & 465 & 0.14 \\
\hline
\end{tabular}

The specific surface area as well as the pore volume of $[\mathrm{Al}, \mathrm{B}] \mathrm{MCM}-22$ determined by $\mathrm{N}_{2}$ adsorption are lower than that of the B-free material (Table 1) and correspond to the ones reported in the literature. The smaller total pore volume of $[\mathrm{Al}, \mathrm{B}] \mathrm{MCM}-22$ than that of [Al]MCM-22 is explained by the smaller diameter of boron atoms substituting, in tetrahedral framework positions, the larger aluminum or silicon T-atoms.

On Fig. 2 the $\mathrm{N}_{2}$ adsorption and desorption isotherms of the parent, dealuminated and B-containing catalysts are presented. As the data show, the decrease in the micropore volume for the mildly steam-treated samples (D350 and D500) determined by $\mathrm{N}_{2}$ adsorption is in the range of 11-17\% (Table 1). Comparing the isotherm of the steamed (D500, D350) and 
subsequently acid-treated samples, it can be concluded that upon acid reflux the micropore volume of the samples practically does not change. Results suggested that the lower $\mathrm{N}_{2}$

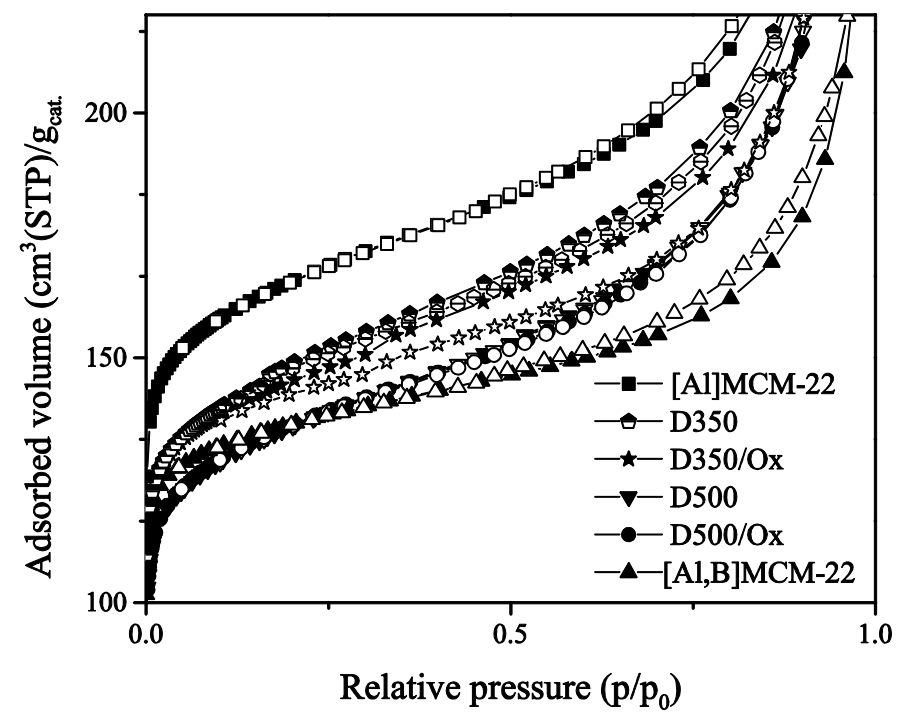

Figure 2. $\mathrm{N}_{2}$ adsorption desorption isotherms of the parent, dealuminated and boroncontaining MCM-22 samples.

adsorption capacity of the dealuminated zeolites is not due to the loss of crystallinity considering the even higher intensity of the XRD reflections of the dealuminated samples. Rather the presence of EFAl entities inside the pores, causing some adsorption limitations even for the small $\mathrm{N}_{2}$ molecule, could be the reason for this effect as was concluded in [20].

\subsection{Acidity}

\subsubsection{Ion Exchange capacity}

The IEC of the zeolites, determined as the amount of evolved ammonia, is usually equivalent to the concentration of Brønsted acid sites in the generated H-forms [21]. The difference between the total aluminum content $(1.08 \mathrm{mmol} / \mathrm{g})$ and the IEC $(0.96 \mathrm{mmol} / \mathrm{g})$ 


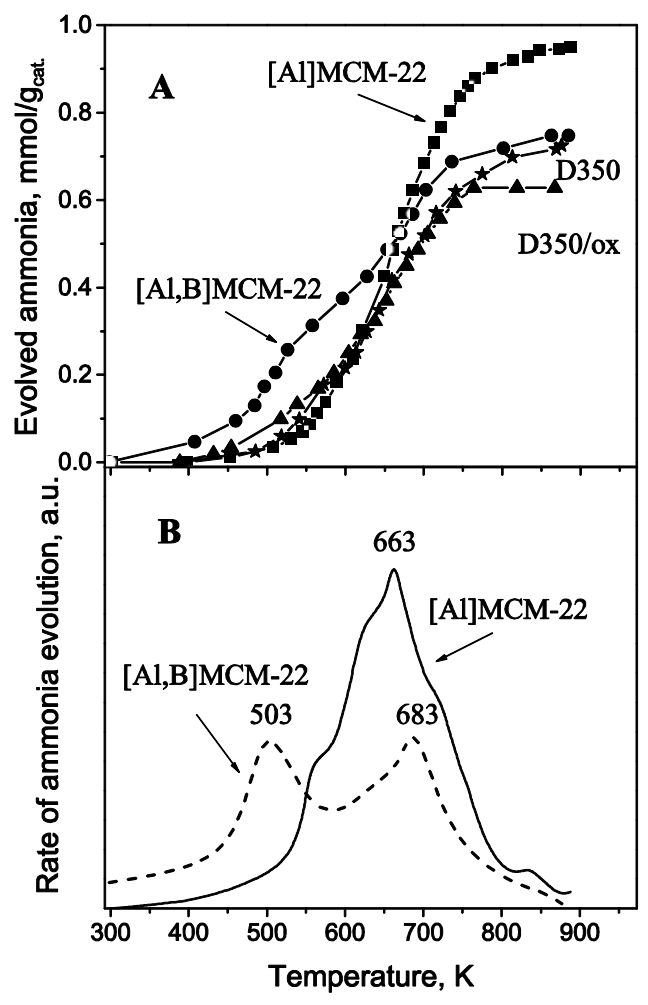

Figure 3. Temperature-programmed ammonia evolution curves $(\mathrm{A})$ and their derivative plots (B) for $\mathrm{NH}_{4}-[\mathrm{Al}] \mathrm{MCM}-22$ and $\mathrm{NH}_{4}-[\mathrm{Al}, \mathrm{B}] \mathrm{MCM}-22$.

of the initial [Al]MCM-22 material indicates that about $11 \%$ of $\mathrm{Al}$ is in extra-framework positions still in the parent calcined sample.

The amount of aluminum in the steamed samples D350 and D500 remains similar to that of the parent material but their ion-exchange capacity decreases significantly by $25 \%$ and $55 \%$, respectively. The results indicate that substantial portion of the $\mathrm{Al}$ atoms has been removed from tetrahedral positions, the higher the more rigorous the hydrothermal treatment.

The subsequent acid leaching results in a similar decrease, by about $40 \%$ of the total Al content, for the acid-treated materials. The results suggest that both extra-framework and tetrahedrally coordinated aluminum atoms have been expelled from the zeolite lattice upon the acid reflux (Table 1).

On Fig. 3A the amount of $\mathrm{NH}_{3}$ evolved upon the TPAE measurement is plotted as a function of temperature. The derivative of the curves, i.e., the plots of desorption rate vs. temperature are also shown (Fig. 3B). The $\mathrm{NH}_{4}^{+}$-form of the [Al]MCM-22 zeolite released ammonia in a broad temperature interval ranging from 523 to $873 \mathrm{~K}$ (Fig. 3A) with a maximum at about $660 \mathrm{~K}$ (Fig. 3B). This maximum corresponds to $\mathrm{NH}_{3}$ evolved from the stronger, Al-connected Brønsted acid sites which concentration is about twice higher in the 
initial, not modified with boron catalyst. Replacement of half of the lattice Al atoms by B leads to reduction of this type of sites. The ammonia desorption from the $\mathrm{NH}_{4}-[\mathrm{Al}, \mathrm{B}] \mathrm{MCM}-$ 22 material exhibit two maxima, the first one at lower temperature (503 K, Fig. 3B). The lowtemperature peak is due to the presence of framework boron generating weaker Brønsted acid sites. This result suggests that the modification with $\mathrm{B}$ in $[\mathrm{Al}, \mathrm{B}] \mathrm{MCM}-22$ possesses substantial amount of weaker Brønsted acid sites on the expense of the stronger ones. Calculations of the number of strong acid sites in the partially B-substituted sample shows $\mathrm{Al}$ content of $0.46 \mathrm{mmol} / \mathrm{g}$, whereas the IEC is $0.75 \mathrm{mmol} / \mathrm{g}$. This is an additional indication that this preparation also contains a substantial amount of weak acid sites due to the isomorphous substitution of Al by B. The effect is quite well visualized in the TPAE curves in Fig. 3.

\subsubsection{FT-IR studies}

In order to obtain information about the type of the acid sites in the parent, steamed and subsequently acid-treated materials, FT-IR spectra before and after Py adsorption were made (Fig. 4). The spectra in the hydroxyl stretching region show (Fig. 4A) that steaming (D350 and D500) results in a strong reduction of the band attributed to bridged $\mathrm{OH}$ groups $(\mathrm{Al}(\mathrm{OH}) \mathrm{Si})$ at $3620 \mathrm{~cm}^{-1}$. Simultaneously, an increase in the intensity of the external Si-OH groups $\left(3745 \mathrm{~cm}^{-1}\right)$ is observed. The following acid treatment step leads to an increased concentration of the internal silanols $\left(3727 \mathrm{~cm}^{-1}\right)$ on the expense of the external $\mathrm{Si}-\mathrm{OH}(3745$ $\mathrm{cm}^{-1}$ ) and to the appearance of new bands at $3700 \mathrm{~cm}^{-1}$ and at $3527 \mathrm{~cm}^{-1}$ in case of the acidleached samples.

The band at $3727 \mathrm{~cm}^{-1}$ is also registered by Meloni at al. [26] in MCM-22 materials with higher $\mathrm{Si} / \mathrm{Al}$ ratio and corresponds to the "hydroxyl nests" detected on steamed [27], acidleached [28] or steam and acid-treated [23] zeolites of the MCM-22 type. In our case the intensity of the band at $3727 \mathrm{~cm}^{-1}$ is the highest for the more severely steam-treated D500/Ox. The FT-IR study combined with the ${ }^{27}$ Al-MAS NMR examinations made by us [19], has led to the conclusion that the effect of the dealumination of MCM-22 zeolite on the $\mathrm{Al}$ atoms distribution consists in: (i) neutralization of part of the bridging $\mathrm{OH}$ groups by cationic extralattice $\mathrm{Al}$ species and (ii) partial transformation of the remaining tetrahedral framework $\mathrm{Al}$ to tri-coordinated lattice aluminum. These Al rearrangements would suggest substantial change in the zeolite activity. 

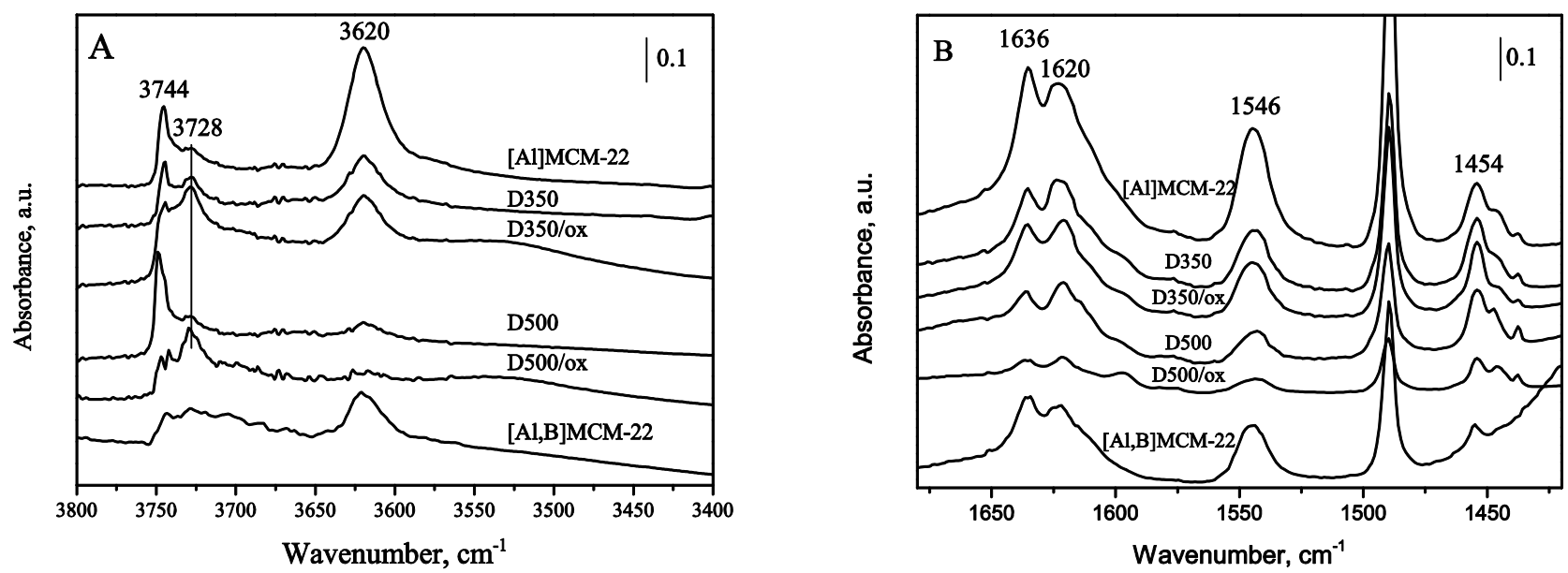

Figure 4. FT-IR spectra of the MCM-22 samples in the $v(\mathrm{OH})$ region after evacuation at $673 \mathrm{~K}$ for $1 \mathrm{~h}(\mathrm{~A})$ and subsequent Py adsorption at $473 \mathrm{~K}$ and degassing at $473 \mathrm{~K}$ for $0.5 \mathrm{~h}(\mathrm{~B})$.

Upon pyridine adsorption the bridged hydroxyl band at $3620 \mathrm{~cm}^{-1}$ disappeared and, indicating the formation of pyridinium ions $\left(\mathrm{PyH}^{+}\right)$, bands of the Py-ring vibrations appeared at $1545(1635) \mathrm{cm}^{-1}$. The further bands at $1454(1622) \mathrm{cm}^{-1}$ are generally assigned to vibrations of Py, bound coordinately to strong Lewis acid sites, i.e., to cationic extraframework aluminum (EFAl) species (often visualized as $\mathrm{AlO}^{+}$). By calculating the integrated absorbance of the bands at $3620 \mathrm{~cm}^{-1}$ and that of the pyridinium bands at $1546 \mathrm{~cm}^{-1}$ in the FT-IR spectra of [A1,B]MCM-22 and [Al]MCM-22 ratio of about 0.5 was found [20] designating that in the boron-containing catalyst half of the Brønsted acid sites are Alconnected. This ratio corresponds to the relative aluminum content of the samples determined by AAS (Table 1). Comparing the intensity of the band at $1454 \mathrm{~cm}^{-1}$ in the FT-IR spectra of the samples (Fig. 4B) it can be concluded that boron-containing sample possesses the lowest amount of Lewis acid sites. These results proved that introduction of boron into MCM-22 lattice reduce both the Brønsted and Lewis acidity (Fig. 4).

The results from the acidity determinations show that dealumination, together with the consecutive acid treatment, as well as the introduction of boron in the zeolite lattice lead to reduction of the total acidity of the parent material. Generation of additional, weakly acidic Brønsted sites on the expense of the stronger ones is observed on the boron containing preparation. 


\subsubsection{Catalytic activity}

The effect of the acidity modification on the activity of the dealuminated and B-substituted series of catalysts for the mixed feed conversion is presented in Fig. 5 and Fig. 6, respectively. The reduction in the total number of Brønsted acid sites in both modifications lead to substantial decrease in the ethylbenzene conversion (Fig. 5A and 6A). A vast enhancement in the contact time for the dealuminated and oxalic-acid treated samples is needed for to reach close activity toward ethylbenzene conversion to that of the initial [Al]MCM-22 (Fig. 5A). As was concluded in [19], the generation of EFAl entities by the steaming procedure not only reduces the number of Al-connected proton sites but also causes, most probably, blocking of the zeolite micropores and leads to significant diminish in the adsorption capacity and catalytic activity.
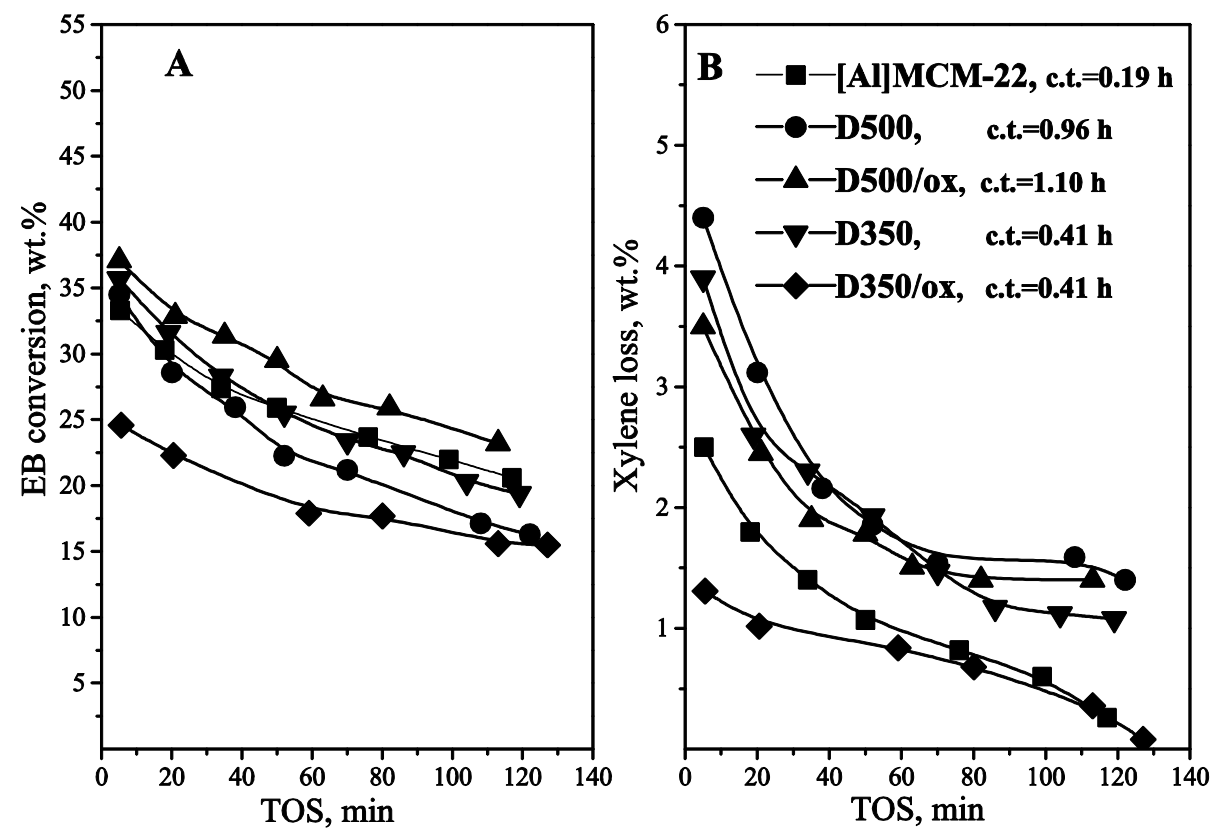

Figure 5. Ethylbenzene conversion (A) and xylene loss (B) as a function of TOS for the dealuminated catalysts at $723 \mathrm{~K}$ and different contact times in the transformation of ethylbenzene-m-xylene mixture $(22: 78 \mathrm{~m} / \mathrm{m} \%)$.

It may be inferred from the catalytic data presented above and in accordance to the FT-IR that the Lewis acid sites created upon steam treatment provoke, with the exception of D350/ox, larger m-xylene loss (Fig. 5B) and faster deactivation (Fig. 5A) without inducing favorable effect on the xylene yield. The partial extraction of these sites by oxalic acid does not restore the active Brønsted sites. It also does not eliminate completely the harmful effect on the xylene isomers yield but only slightly reduce it (Fig. 5). 

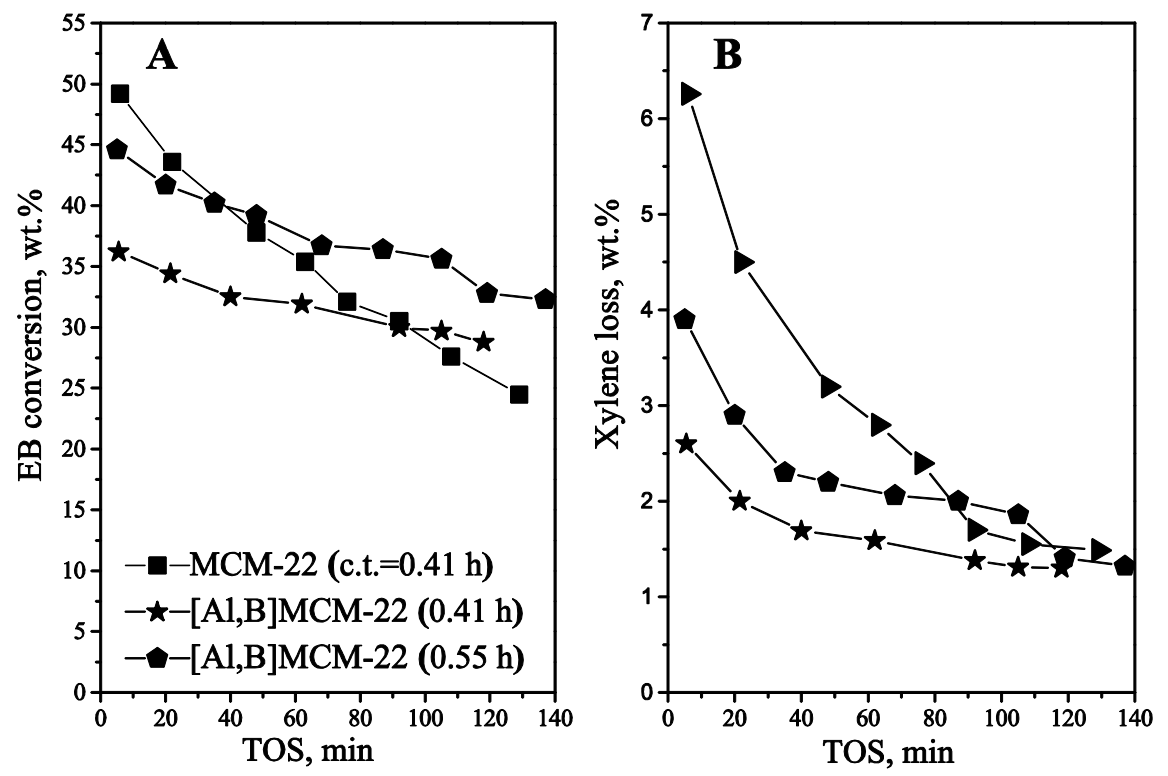

Figure 6. Ethylbenzene conversion (A) and xylene loss (B) as a function of TOS for the Bcontaining catalysts at $723 \mathrm{~K}$ and different contact times in the transformation of ethylbenzene-m-xylene mixture $(22: 78 \mathrm{~m} / \mathrm{m} \%)$.

In Fig. 6 comparison of the catalytic performance of the parent and boron-containing catalyst by equalizing the EB conversion with varying the contact time is made. In accordance to the FT-IR acidity determinations, the data presented above prove that the reduction of the number of strong Brønsted acid sites and the lack of Lewis acidity (Fig. 4B) together with the presence of weaker sites (Fig. 3) are obviously the reasons for the improved catalytic performance of $[\mathrm{Al}, \mathrm{B}] \mathrm{MCM}-22$. It consists in lower xylene loss and much higher catalytic stability, positive effects studied in a wider range of contact times and EB conversion degrees for two reaction temperatures (Fig. 7). 


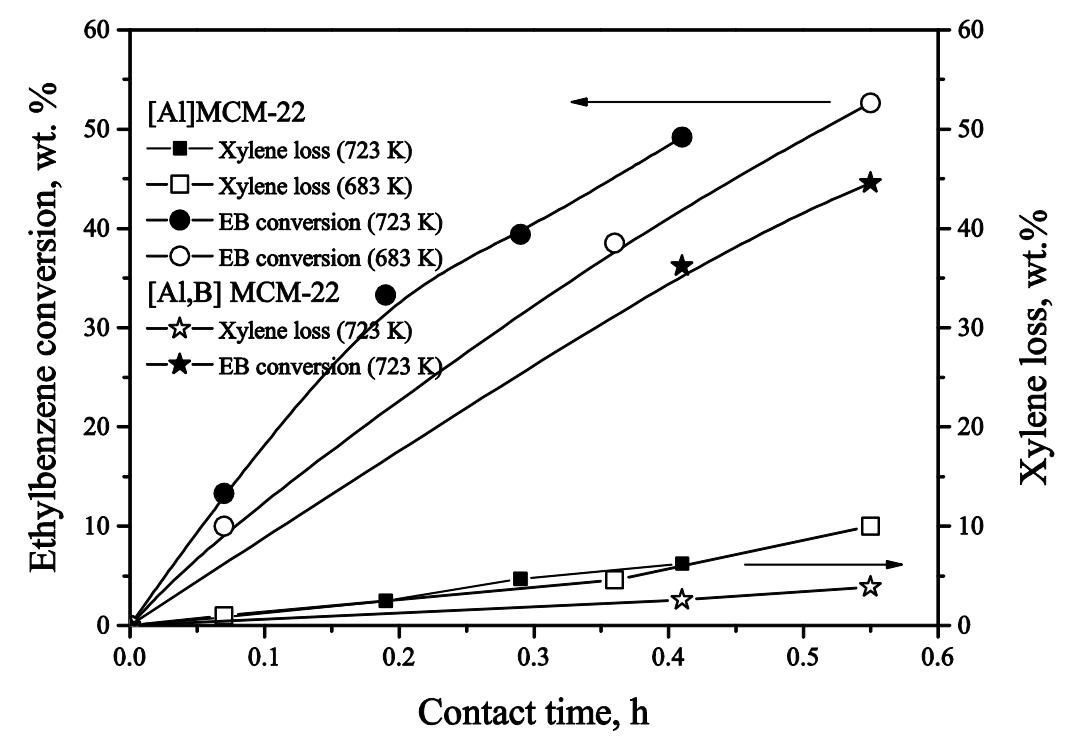

Figure 7. Ethylbenzene conversion (filled symbols) and xylene loss (empty symbols) in the transformation of ethylbenzene-m-xylene mixture $(22: 78 \mathrm{~m} / \mathrm{m} \%)$ at $683 \mathrm{~K}$ and $723 \mathrm{~K}$ over [Al]MCM-22 and [Al,B]MCM-22 as a function of contact times.

Thus, it may be concluded that the introduction of boron in lattice positions is more effective way of modification, compared to dealumination, as an approach to get milder acidity, appropriate for the conversion of EB-m-xylene mixed feed. The absence of Lewis acid sites (Fig. 4B), the generation of weaker Brønsted acid sites and the reduction of the micropore volume are, most possibly, the main favorable factors responsible for the limitation of the detrimental side reactions of transalkylation and coking in which xylene products participate intensely.

The distribution of the reaction products on the parent and modified catalysts at close EB conversion is presented in Table 2. The selectivity to side products formed in transethylation and xylene disproportionation is higher over the dealuminated samples compared to the parent material. The much higher than one molar ratio between toluene and trimethylbenzene (TMB) for all catalysts is an indication that not only direct xylene disproportionation to those two products takes place, but also secondary reactions of toluene formation by transmethylation of benzene or ethylbenzene with xylenes have proceeded in accordance to Silva et al. [5] and Benazzi et al. [4] respectively.

Table 2. Products distribution at the $5^{\text {th }}$ min from the start of the reaction of ethylbenzene-m-xylene feed $(22: 78 \mathrm{~m} / \mathrm{m} \%)$ transformation at close ethylbenzene conversion attained at different contact times. 


\begin{tabular}{|c|c|c|c|c|c|c|}
\hline Contact times, $\mathrm{h}$ & 1.1 & 0.96 & 0.41 & 0.41 & 0.29 & 0.41 \\
\hline Catalysts & $\mathrm{D} 500^{\mathrm{b}}$ & $\mathrm{D} 500(\mathrm{Ox})^{\mathrm{b}}$ & {$[\mathrm{Al}, \mathrm{B}] \mathrm{MCM}-22^{\mathrm{b}}$} & $\mathrm{D} 350^{\mathrm{b}}$ & {$[\mathrm{Al}] \mathrm{MCM}-22^{\mathrm{b}}$} & $\mathrm{Pt} /[\mathrm{Al}] \mathrm{MCM}-22^{\mathrm{c}}$ \\
\hline \multicolumn{7}{|l|}{ Products (wt.\%) } \\
\hline Ethane & 1.93 & 1.46 & 1.89 & 1.77 & 2.15 & 2.79 \\
\hline Benzene & 5.25 & 4.41 & 4.76 & 4.33 & 4.89 & 5.53 \\
\hline Toluene & 3.53 & 4.3 & 3.09 & 4.05 & 4.62 & 5.4 \\
\hline Ethylbenzene & 14.14 & 14.47 & 13.97 & 13.63 & 13.09 & 11.79 \\
\hline Xylenes & 74.67 & 74.38 & 75.98 & 75.62 & 74.66 & 75.26 \\
\hline Trimethylbenzenes & 0.27 & 0.63 & 0.26 & 0.59 & 0.44 & 0.09 \\
\hline Ethyltoluenes & 0.20 & 0.34 & 0.04 & 0.06 & 0.14 & 0.12 \\
\hline EB conversion, $\%$ & 37.1 & 34.5 & 36.2 & 35.7 & 39.4 & 45.9 \\
\hline Xylene loss, \% & 3.5 & 4.4 & 2.6 & 3.9 & 4.6 & 3.6 \\
\hline $\begin{array}{l}\text { Degree of p-xylene } \\
\text { approach to } \\
\text { equilibrium, \% } \\
\text { (Eq. }=25.5 \%)\end{array}$ & 74.5 & 75.0 & 81.0 & 65.7 & 76.9 & 82.0 \\
\hline$\%$ isomerisation $^{a}$ & 32.4 & 35.0 & 40.4 & 32.2 & 36.9 & 53.1 \\
\hline $\begin{array}{c}\text { p:o-xylene ratio } \\
(\mathrm{Eq}=0.96)\end{array}$ & 1.4 & 1.1 & 1.05 & 1.0 & 1.03 & 1.01 \\
\hline
\end{tabular}

Considering the data in Table 2, it can be inferred that the lowest xylene loss registered on the B-containing catalyst results from the limitation of the above side reactions. Replacement of the strong Al-connected acid sites by weaker ones is most probably the reason for the favorable restriction of alkyl transfer over [A1,B]MCM-22.

Analogous effect of selective improvement in xylene isomerization and significant reduction in xylene loss by effective elimination of the strong acid sites of zeolite ZSM-5 is observed by Bauer et al. [28]. The authors also introduce hydroisomerisation function by loading Pt to the modified support. The ability of platinum for converting EB to xylenes is well known [29] and zeolites impregnated with this noble metal are widely studied in reactions of mixed EB-m-xylene feeds transformation [4,5,7,30]. As it was expected, the introduction of Pt into our [Al]MCM-22 leaded to higher net gain of products of EB conversion through dealkylation and transalkylation as well as isomerization to the aimed xylenes (Table 2) as the above authors have observed for ZSM-5, BEA and mordenite 
catalysts. Pt-modified [Al]MCM-22 possesses highest isomerization activity and degree of pxylene approach to equilibrium at $40^{\circ} \mathrm{C}$ lower reaction temperature. In accordance with the reduced formation of bulky transalkylation products, the main cause for coke accumulation, this catalyst shows very high stability, same as that of [Al,B]MCM-22 presented in Fig. 6.

\section{Conclusions}

On the basis of the obtained results, it can be concluded, that zeolite [Al]MCM-22 and especially its Pt-loaded modification possess promising properties for ethylbenzene-m-xylene mixture transformation. The appropriate acidity spectrum and structure of zeolite [Al]MCM-22 and the presence of hydrogenation sites provide adequate degree of EB conversion (about 40\%) and p-xylene approach to equilibrium (above 70\%) at low xylene loss (less than $5 \%$ ) for the studied interval of reaction conditions.

[A1,B]MCM-22 possesses better catalytic performance than the parent zeolite [Al]MCM-22 because, most probably, of the presence of lower number of strong, Alconnected acid sites and weaker boron-generated acid sites. The presence of the latter ones and the absence of Lewis sites restrict the side reactions leading to xylene product loss. At close degree of EB conversions, the B-containing catalyst displays higher degree of m-xylene isomerization and respectively p-xylene approach to equilibrium compared to the other catalysts not containing $\mathrm{Pt}$, as well as lowest xylene loss. Its catalytic performance competes with that of the Al-analogue loaded with the expensive precious Pt metal. Studies on Ptmodified $[\mathrm{Al}, \mathrm{B}] \mathrm{MCM}-22$ are in progress.

Steam dealumination with or without consecutive acid treatment is not an appropriate procedure for preparation of efficient catalysts of the MCM-22 type for the reaction of EB-mxylene feed conversion. The substantial loss of Brønsted acid sites and the appearance of Lewis sites have disadvantageous consequences on their catalytic performance consisting in strongly reduced activity towards EB transformation, high xylene loss and fast deactivation.

\section{Acknowledgment}

Support of this work in the framework of the Hungarian-Bulgarian Inter-Academic Exchange Agreement (project no. 9) is gratefully acknowledged. 


\section{References}

[1] T. Hibino, N. Niwa, Y. Murakami, J. Catal. 128 (1991) 551-558.

[2] E. Benazzi, S. De Tavernier, P. Beccat, C. Nedez, A. Choplin, J.M. Basset, Chemtech 24 (1994) 13-18.

[3] H.H. John, H.D. Neubauer, P. Birke, Catal. Today 49 (1999) 211-220.

[4] E. Benazzi, J.M. Silva, M.F. Ribeiro, F. Ramôa Ribeiro, M. Guisnet in: L. Bonneviod and S. Kaliaguine (Eds), Zeolites: A Refined Tools for Designing Catalytic Sites, Elsevier Sci. B.V., (1995), pp. 393-400.

[5] J.M. Silva, M.F. Ribeiro, F. Ramôa Ribeiro, E. Benazzi, M. Guisnet, Appl. Catal. A 125 (1995) 1-14.

[6] N. Sharanappa, S. Pai, V.V. Bokade, J. Mol. Catal. A 217 (2004) 185-191.

[7] A. Geetha Bhavani, A. Pandarangan, J. Mol. Catal. A 267 (2007) 209-217.

[8] E. Guillon, S. Lacombe, T. Sozinho, P. Magnoux, S. Gnep, P. Moreau, M. Guisnet, Oil Gas Sci. Technol.- Rev. IFP. 64 (2009) 731-744.

[9] R.M. Mihályi , Sz. Klébert, M. Kollár, V. Mavrodinova, J. Por. Mater. (2013) submitted. [10] T.F. Degnan, J.G. Santiesteban, J.S. Beck, S. Buchanan, J. Cheng, A. Dandekar, Process Devel. Symp.: Accelerating Process Development for Growth, AIChE (2003) pp. 167-182.

[11] A. Corma, V. Fornes, S.B. Pergher, T.L.M. Maesen, J.G. Buglass, Nature 396 (1998) 353-356.

[12] S.-H. Park, H.-K. Rhee, Appl. Catal. A 219 (1-2) (2001) 99-105.

[13] P. Matias, J.M. Lopes, P. Ayrault, S. Laforge, P. Magnoux, M. Guisnet, F. Ramôa Ribeiro, Appl. Catal. A 365 (2009) 207-213.

[14] S.M. Campbell, D.M. Bibby, J.M. Coddington, R.F. Howe, R.H. Meinhold, J. Catal. 161 (1996) 338-349.

[15] L.D. Fernandes, J.L.F. Monteiro, E.F. Sousa-Aguiar, A. Martinez, A. Corma, J. Catal. 177 (1998) 363-377.

[16] V. Machado, J. Rocha, A.P. Carvalho, A. Martins, Appl. Catal. A 445-446 (2012) 329338.

[17] C.S. Carriço, F.T. Cruz, M.B. Santos, H.O. Pastore, H.M.C. Andrade, A.J.S. Mascarenhas, Microporous Mesoporous Mater. 181 (2013) 74-82.

[18] L. Liu, M. Cheng, D. Ma, G. Hu, X. Pan, X. Bao, Microporous Mesoporous Mater. 94 (2006) 304-312. 
[19] R.M. Mihályi, M. Kollár, P. Király, Z. Károly, V. Mavrodinova, Appl. Catal. A 417-418 (2012) 76-86.

[20] I. Kolev, V. Mavrodinova, M.R. Mihályi, M. Kollár, Microporous Mesoporous Mater. 118 (2009) 258-266.

[21] H.G. Karge, in: G. Öhlmann, H. Pfeifer, R. Fricke (Eds.), Catalysis and Adsorption by Zeolites, Studies in Surface Science and Catalysis, Elsevier, Amsterdam, 1991, pp. 133-156.

[22] R. Ravishankar, D. Bhattacharya, N. Jacob, S. Sivasankar, Microporous Mesoporous Mater. 4 (1995) 83-93.

[23] P. Wu, T. Komatsu, T. Yashima, Microporous Mesoporous Mater. 22 (1998) 343-356.

[24] M.A. Camblor, A. Corma, M.J. Dias-Cabanas, J. Phys. Chem. B, 102 (1998) 44-51.

[25] L.Z. Chen, Y.Q. Feng, Zeolites, 12 (1992) 347-350.

[26] D. Meloni, S. Laforge, D. Martin, M. Guisnet, E. Rombi, V. Solinas, Appl. Catal. A 215 (2001) 55-66.

[27] P. Mériaudeau, Vu A. Tuan, Vu T. Nghiem, F. Lefevbre, Vu T. Ha, J. Catal. 185 (1999) 378-385.

[28] F. Bauer, W.-H. Chen, H. Ernst, S.-J. Huang, A. Freyer, S.-B Liu, Microporous Mesoporous Mater. 72 (2004) 81-89.

[29] K. Robsclager, E. Christoffel, Ind. Eng. Chem. 18 (1979) 347-352.

[30] K. Mirth, A. Halgeri, T. Prasada Rao, Indian J. Technol. 21 (1983) 379-386. 